\section{EARLY ASTRONOMY}

$\mathrm{T}$ $\mathrm{HE}$ third of the series of articles on early astronomy appearing in Sky and Telescope, published in the February issue, deals with the Polynesians (see also Nature, April 15, p. 459). In this article it is shown that, contrary to earlier views, these people had an intimate knowledge of the constellations and hundreds of stars. They studied the motions of the planets and the phases of the moon, which were used to indicate lapses of time, and they possessed an extraordinary aptitude for making meteorological forecasts.

In navigation the Polynesians displayed remarkable skill; their method of sailing was usually to steer north or south until they reached the latitude of the chosen island, and then to steer east or west. They made use of the "sacred calabash" for deter. mining the latitude. This consisted of a large gourd in which four holes were bored at the same height near the neck. An accurate horizontal plane was provided by the level of the water at these holes, and a sight through a hole over the opposite edge at a bright star gave the angle of its height above the horizon. By placing the holes at the correct distance below the edge to indicate the latitude of their destination, they knew when to turn east or west to reach the island of their quest. Their long sea journeys proved that the earth was round thousands of years ago.

The Polynesians nearly everywhere commenced the new year on December 1, with the first new moon after the first appearance of the Pleiades in the eastern sky in the evening twilight. In the Hawaiian islands twelve lunar months of thirty days each were used, and the religious year was correlated with the sidereal year by introducing five extra days. The months were divided into three periods of ten days each. The origin of the world was explained by various legends, but some of the fundamental ideas were similar, and a primitive egg was the natural beginning. The darkness of the earth was removed by the raising of the sky and letting in the light of dawn.

In the March issue of Sky and Telescope there is a brief reference to the astronomy of the Chinese, Indians, Phœnicians, Greeks and Egyptians. Although the inclination of the ecliptic was determined very accurately by Chou Kung in 1100 B.o., yet this eminent mathematician failed completely in his estimate of the sun's distance, as he calculated from the hypothesis of a flat earth. It is remarkable that, though the Phœenicians were expert navigators, yet they have left no other evidence of their astronomical knowledge.

A few of the attainments of the outstanding astronomers and mathematicians of Greece and Egypt are mentioned in this article, and among these we may refer to Aristarchus of Samos, born in 310 B.c., who attempted to measure the relative distances of the moon and sun by a principle theoretically sound, but beset with practical difficulties which rendered it useless. He assumed that at halfmoon the angle at the moon between the directions of the sun and the earth was $90^{\circ}$, and if he could measure the angle subtended at the earth by the lines earth-moon and earth-sun, he could solve the triangle of which one angle was a right angle. Unfortunately, a very small error in either of these angles would be responsible for a considerable error in deter. mining the relative distances of the sun and moon, because the ratio of their distances depends on the small angle at the sun subtended by the earth.moon line, and this angle is very sensitive to errors in either of the other angles. Aristarchus obtained a value of the ratio of the distances of the moon and sun which was about twenty times too great, thus making the sun very close to the earth-about twenty times the moon's distance. Aristarchus had the courage to suggest publicly that the earth was a planet and revolved round the sun like the other planets-a view for which he was charged with impiety.

\section{THE WHITE BUTTERFLY IN NEW ZEALAND}

TN the New Zealand Journal of Science and Tech1 nology of June 1943, J. Muggeridge, of the Department of Scientific and Industrial Research, gives an account of the introduction of parasites of the small cabbage white butterfly (Pieris raxa) into New Zealand. Two species of parasite are taken into consideration, namely, the Braconid Apanteles glomeratus and the Chalcid Pteromalus puparum. Following the entry of the same species of white butterfly into North America, the Braconid species just mentioned was introduced from Europe in an effort to obtain a measure of control over the pest in question.

There seems little doubt regarding the soundness of this procedure since the insect is considered to be one of the most important agents destroying the caterpillars in North America to-day. This conclusion naturally suggested the possibility that the Apanteles would similarly parasitize, and so destroy, the caterpillars of the butterfy in New Zealand. Acting on these foundations, upwards of half a million cocoons of the Apanteles were introduced from England into New Zealand during the years 1931-34. Liberations were made in various localities, but in spite of intensive field surveys the creature appears to be no longer present.

During 1938-39 about six thousand American-bred Apanteles were introduced, and all the evidence indicates that these have become successfully established. The behaviour of the European Apanteles glomeratus contrasts sharply, therefore, with that of the American-bred form. The Pteromalus is a parasite of the pupa of the butterfly. Its larva kills the pupa and the adult Chalcid emerges through a small hole made in or near the region of the wing of the future butterfiy. The male Chalcids remain near the pupæ from which they have issued and wait there for the appearance of the females with which they mate. This parasite was sent to New Zealand while still within the pupæ of the butterfly and was first introduced during 1932-33 when about five hundred of these chrysalides were shipped. From out of these hosts more than twelve thousand adult parasites emerged and nearly nine thousand were liberated in the field in 1933. From a field survey made at the latter end of the same season it was found that out of 415 collected butterfly pupæ 58 per cent had become parasitized. The species thus became established with remarkable rapidity and is exercising a useful degree of control. As the author remarks, it has spread rapidly from the points where liberations were originally made, even as far as eighty miles in the first season, and it has had a marked influence in reducing the butterfly population and the damage 